\title{
PERANCANGAN MEDIA PROMOSI PERUSAHAAN ARNIS WIGATI (AW)
}

\author{
Aziz Adisurianto Hakim ${ }^{1}$, Yanuar Rahman ${ }^{2}$ \\ 1,2 Universitas Telkom
}

\begin{abstract}
Abstrak: Kain Tenun merupakan hasil kerajinan berupa kain yang terbuat dari benang yang di tenun. Kain tenun diproduksi di berbagai daerah di Indonesia seperti Sumatera, Jawa, Kalimantan, Sulawesi, Flores dan Lombok. Arnis Wigati (AW) merupakan pelaku usaha di bidang fashion khusus busana wanita yang memadukan antara motif kain tenun dengan gaya kontemporer. Sebagai salah satu ethnic brand di Indonesia, AW masih membutuhkan promosi untuk meningkatkan awareness di masyarakat khususnya melalui perancangan media promosi. Metode yang digunakan dalam pengumpulan data yaitu observasi dan wawancara sebagai teknik pengumpulan data. Metode analisis data yang digunakan adalah analisis SWOT dan analisis matriks perbandingan antara AW dengan brand fashion sejenis. Hasil rancangan penelitian ini utamanya berupa perancangan media promosi dalam bentuk media digital antara lain blog dan social media ads sebagai solusi terhadap permasalahan perusahaan. Perancangan media promosi ini diharapkan dapat membantu meningkatkan brand awareness AW.
\end{abstract}

Kata Kunci : media promosi, online, kain tenun, etnik.

\begin{abstract}
Kain Tenun is a type of fabric made from woven yarn. In Indonesia there is so many regions that produced this woven yarn such as Sumatra, Jawa, Kalimantan, Sulawesi, Flores and Lombok. One entrepreneur who makes this Kain Tenun is Arnis Wigati (AW) who produces and sells various types of women's clothing, especially clothing that combines woven fabrics in a contemporary style. As one ethnic brand in Indonesia, AW still need promotion to increase awareness in the community, especially through the design of promotional media. To achieve the proper results, this study uses several methods including data collection, observation and interviews. This research using SWOT analysis and matrix analysis comparison between AW with other fashion brands to get representative data analysis results. The results of this research is the design of promotional media in digital form, such as blogs, instagram advertising, twitter advertising and other social media advertising as one of the solutions to the promotional problems in the company. This media campaign design is to be expected help increasing the brand awareness of AW.
\end{abstract}

Keywords : promotional media, online, tenun fabric, etchnic.

Penulis adalah mahasiswa dan staf pengajar jurusan Desain Komunikasi Visual, Fakultas Industri Kreatif Universitas Telkom, email: zioria.zioria@gmail.com, vidiyan@telkomuniversity.ac.id 


\section{PENDAHULUAN}

\section{Latar Belakang}

Indonesia merupakan negara yang sangat kaya akan budaya dan tersebar dari Sabang hingga Merauke. Salah satu kekayaan itu adalah kain tenun yang merupakan hasil kerajinan berupa kain yang terbuat dari benang yang di tenun. Tenun merupakan teknik dalam pembuatan kain yang dibuat dengan prinsip sederhana, yaitu dengan menggabungkan benang secara memanjang dan melintang dengan bersilangnya antara benang, lungsi dan pakan secara bergantian. Beberapa jenis tenun antara lain songket, tenun ikat, tenun dobel ikat, dan pakan. Kain tenun tersebut diproduksi di berbagai daerah di Indonesia seperti Sumatera, Jawa, Kalimantan, Sulawesi, Flores dan Lombok.

Seiring dengan perkembangan zaman, kain tenun tersebut semakin kalah bersaing dengan masuknya produk kain impor. Dengan demikian produk kain tenun pun lama-kelamaan berkurang peminatnya, dan secara otomatis para produsen pun akan mengurangi hasil produksinya. Berkurangnya hasil produksi, membuat kain tenun memiliki harga yang relatif lebih mahal, variasi motif yang monoton, hingga menyebabkan pangsa pasar kain tenun semakin sempit dan terbatas (Hendraswati, 2012: 2).

Fenomena tersebut membuat sebagian masyarakat bersimpati untuk melestarikan kain tenun, mulai dari perorangan, komunitas, lembaga pendidikan hingga pelaku usaha. Salah satu pelaku usaha tersebut adalah AW (Arnis Wigati), yang merupakan ethnic brand khusus fashion busana wanita yang memadukan motif kain tenun dengan gaya kontemporer. AW dibuat oleh Arnis Wigati pada Desember 2014 dan setiap koleksi busananya dibuat dengan jumlah terbatas, agar wanita yang memakai busananya merasa menjadi seorang wanita yang istimewa. Sebagai ethnic brand di Indonesia, AW diharapkan terus berinovasi dan berpromosi untuk meningkatkan awareness di masyarakat. 
AW baru menggunakan media sosial sebagai wadah promosi. Menurut Kotler dan Armstrong (2008) untuk dapat menghasilkan respons yang diinginkan di pasar sasaran, bauran pemasaran (marketing mix) merupakan kumpulan alat pemasaran taktis terkendali yang dapat dipadukan oleh perusahaan. Bauran pemasaran yang digunakan untuk produk antara lain adalah product, price, promotion dan place. Berdasarkan uraian tersebut, pemasaran yang dilakukan AW masih belum efektif, karena alat-alat bauran pemasaran belum semuanya digunakan perusahaan khususnya promosi yang belum maksimal.

Menurut Kotler, (2001:98-100) pemasaran yang efektif menggunakan bauran promosi antara lain periklanan (Advertising), penjualan tatap muka (personal selling), publisitas (publicity), promosi penjualan (sales promotion), dan pemasaran langsung (direct marketing). Pada prinsipnya promosi bertujuan membujuk calon klien, memperkenalkan perusahaan, dan membentuk tingkah laku serta mengingatkan kembali tentang produk dan perusahaan (Sistaningrum, 2002:98). Dari berbagai permasalahan dirasa perlu adanya perancangan media promosi untuk membantu meningkatkan awareness perusahaan AW.

\section{Metode Penelitian Dan Metode Analisis}

Beberapa metode yang akan digunakan dalam pengumpulan data yaitu studi literatur, observasi, wawancara. Studi Literatur adalah kemampuan manusia untuk mengurai dan menggabungkan, memungkinkan untuk membuat teori baru dari teori yang sudah ada, dari hasil membaca (Soewardikoen, 2013 : 6). Studi literatur dilakukan dengan cara mencari teori yang berhubungan dengan permasalahan yang ada di AW, dan bertujuan untuk menyimpulkan suatu hipotesa baru.

Menurut Soewardikoen (2013:6) Observasi adalah mengumpulkan data yang kemudian diolah menjadi sebuah informasi. Dalam hal penelitian visual 
adalah mengumpulkan data visual atau gambar. Gambar dilihat secara teliti, memberikan sensasi kepada otak untuk diolah menjadi persepsi dan dirangkai menjadi informasi.

Wawancara adalah instrumen penelitian. Kekuatan wawancara adalah penggalian pemikiran, konsep dan pengalaman pribadi pendirian atau pandangan dari individu yang diwawancara. Mencoba mendapatkan keterangan secara lisan dari narasumber, dengan bercakap-cakap dan berhadapan muka dengan Arnis Wigati selaku CEO AW. (Soewardikoen, 2013 dalam Koentjaranigrat, $1980: 165)$.

Metode analisis yang digunakan adalah analisis SWOT dan analisis matriks. Analisis SWOT adalah suatu bentuk analisis di dalam manajemen perusahaan atau di dalam organisasi yang secara sistematis dapat membantu dalam usaha penyusunan suatu rencana yang matang untuk mencapai tujuan, baik itu tujuan jangka pendek maupun tujuan jangkan panjang. Menurut Soewardikoen (2013) dalam buku Metodologi Penelitian Visual, Analisis SWOT memperhitungkan faktor internal yang terdiri dari Strenght dan Weakness serta faktor luar yang terdiri dari Opportunity dan Threat.

Melalui metode analisis matriks adalah dengan membandingkan media visual promosi terdahulu, membandingkan dengan brand sejenis, dan melakukan penarikan kesimpulan dari hasil pengamatan yang dilakukan kepada perusahaan AW. Melalui metode analisis matriks adalah dengan membandingkan media visual promosi terdahulu, membandingkan dengan brand sejenis, dan melakukan penarikan kesimpulan dari hasil pengamatan yang dilakukan kepada perusahaan AW. 


\section{TEORI PERANCANGAN}

a) Pemasaran. Menurut Kotler, (2016:27) pemasaran merupakan proses mengidentifikasi dan menghubungkan manusia dan kebutuhan sosialnya. Pemasaran adalah aktifitas dan proses untuk membuat, mengkomunikasikan, menyampaikan, dan bertukar informasi yang mempunyai nilai untuk konsumen, klien, mitra dan masyarakat.

b) Perilaku Konsumen. Perilaku konsumen adalah segala sesuatu yang berhubungan dengan proses pengambilan keputusan baik itu ketika persiapan pembelian produk termasuk dalam perilaku konsumen. (Shiffman dan Kanuk, 2000)

c) Inbound Marketing. Menurut Hubspot, sebuah perusahaan Internasional yang menangani pemasaran digital, Inbound Marketing merupakan strategi untuk membuat calon konsumen lebih tertarik mencari produk kita melalui optimasi berbagai media di platform digital.

d) Media. Di era perkembangan digital, ada satu media baru muncul dan menjadi media yang banyak digunakan yaitu media sosial yang merupakan sebuah media online, di mana para penggunanya (user) melalui aplikasi berbasis internet dapat berbagi, berpartisipasi, dan menciptakan konten berupa blog, wiki, forum, jejaringsosial, dan ruang dunia virtual yang disokong oleh teknologi multimedia. (Mulyani, 2014 : 25).

e) DKV. Desain Komunikasi Visual (DKV) adalah ilmu yang mempelajari konsep komunikasi dan ungkapan daya kreatif, yaang di aplikasikan dalam pelbagai media komunikasi visual dengan mengolah elemen desain grafis yang terdiri warna, huruf dan tipografi, gambar (ilustrasi), dan layout. Semua itu dilakukan guna menyampaikan pesan secara visual kepada target sasaran. (Tinarbuko, 2009:23) 


\section{DATA DAN ANALISIS}

AW merupakan ethnic brand khusus fashion busana wanita yang memadukan antara motif kain tenun dengan gaya kontemporer. AW dibuat oleh Arnis Wigati pada bulan Desember 2014 berlokasi AW terletak di Jalan Teluk Bone No. 55C Pasar Minggu Jakarta Selatan 12520.

Selama ini AW baru melakukan promosi melalui keikutsertaan di beberapa event fashion media sosial Instagram. Informasi yang diberikan adalah tentang katalog produk dari AW dan kegiatan kegiatan perusahaan. Melalui keikutsertaan AW di event-event fashion seperti: Cleo Festival (majalah Cleo), I Project Bazaar (di gedung perkantoran Sampoerna Strategic Square), Local Brand Bazaar (di Swissbell Hotel), MNC Local Brand Bazaar (di MNC TV). Melalui liputan media seperti acara Dua Hijab di Trans 7, berita video di Viva News dan koran Republika di halaman Trend. Melalui marketplace (Qlapa.com) serta media sosial Instagram, pengetahuan tentang brand AW tersebar secara word of mouth.

Promosi yang digunakan AW menggunakan tema cerita untuk menyampaikan nilai-nilai pada produknya yaitu filosofia dan jelajah nusantara. Kedua tema ini digunakan bergantian maupun paralel sesuai momen yang diminati oleh konsumen AW yaitu wanita, umur 25-35, dengan status sosial menengah ke atas dan gaya hidup perkotaan, suka berkumpul atau bersosialisasi, peduli akan fashion, dan ingin menjadi pusat perhatian.

Hasil wawancara yang dilakukan penulis terhadap narasumber menunjukan minat wanita Indonesia akan busana etnik atau tradisional masih kurang, salah satunya adalah minat akan pakaian berbahan dasar tenun. Dari hasil analisis matriks yang dilakukan, penulis memutuskan untuk menggunakan strategi pemanfaatan teknologi untuk meningkatkan kuantitas dan kualitas penyampaian cerita dan filosofi produk AW sehingga dapat menjangkau calon konsumen segmen kelas menengah yang akrab dengan media sosial dan media digital. 


\section{KONSEP}

a). Konsep Pesan. Pesan utama akan mengangkat tema "Jelajah Nusantara melalui tenun sebagai budaya modern yang mengikuti perkembangan zaman". Konsep pesan ini mengimplementasikan tentang bagaimana calon konsumen AW diajak untuk mengenal nusantara melalui produk AW. Tema jelajah nusantara digunakan karena dapat dengan mudah diterima oleh calon konsumen AW yaitu masyarakat Indonesia.

b). Konsep Kreatif. Konsep kreatif yang digunakan memakai tema pesta. Pesta yang dipilih identik dengan budaya Indonesia sesuai konsep jelajah nusantara, salah satunya acara pernikahan atau akrab dikenal di daerah perkotaan dengan "Kondangan".

c). Konsep Visual. Konsep visual yang dibuat akan dibagi menjadi dua yaitu untuk identitas visual logo dan visual media promosi. Konsep visual AW yaitu dengan menggabungkan antara motif tradisional tenun dengam warna-warna kontemporer. Motif tenun yang akan digunakan yaitu motif tenun dari Riau.

1. Elemen visual yang digunakan menggunakan Tenun Riau. Unsur dari tenun melayu merupakan segala sesuatu yang berasal dari alam, salah satunya adalah flora yang dapat merepresentasikan keindahan alam Indonesia. Beberapa unsur yang digunakan antara lain Pucuk Rebung, Kelopak jambu Air, Tampuk Manggis dan Tampuk Manggis Bersusun.

2. Warna yang digunakan adalah warna yang memberi kesan kontemporer. Warna merah muda merupakan warna primer sedangkan warna hitam, abu-abu, emas, biru muda dan putih merupakan warna sekunder. 
3. Tipografi yang digunakan adalah font Nexa Bold karena memiliki keter-bacaan mudah dengan karakter huruf lembut dan tegas serta modern.

4. Layout yang digunakan menyesuaikan sesuai dengan konsep yang diterapkan yaitu filosofis tradisional dan kontemporer. Maka perancangan layout yang digunakan yaitu layout asimetris yang identik dengan kesan modern.

5. Ilustrasi yang digunakan adalah fototografi portrait dengan menggunakan model wanita.

d). Konsep Media. Pada perancangan media promosi AW ini menggunakan strategi Inbound Marketing yang di dalamnya terdapat Blog dan Sosial Media Ads (Facebook Ads, Instagram Ads, Twitter Ads dan Google Ads).

\section{HASIL PERANCANGAN}

1. Blog

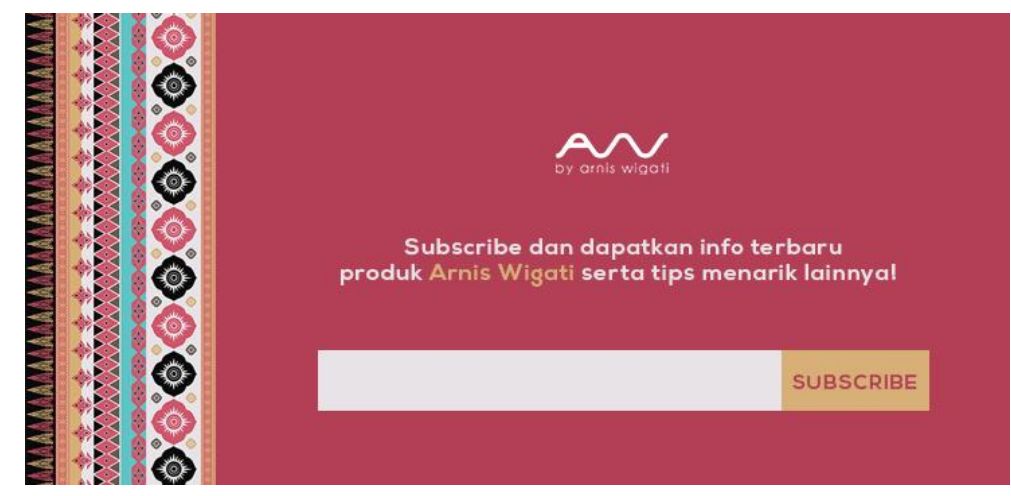

Gambar 5.1 Pop Up Call to Action Blog 


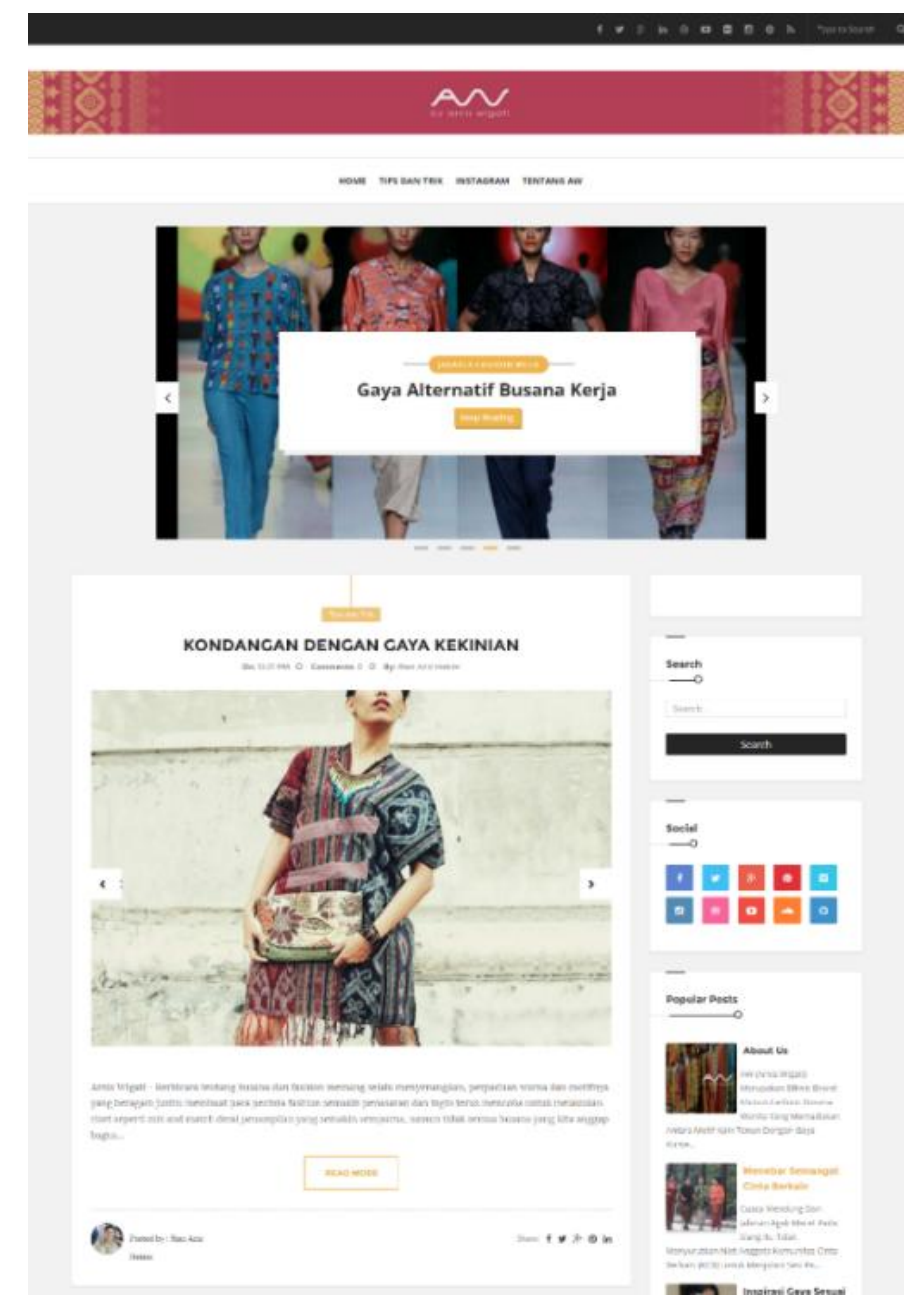

Gambar 5.2 Interface Blog

2. Facebook dan Twitter Ads

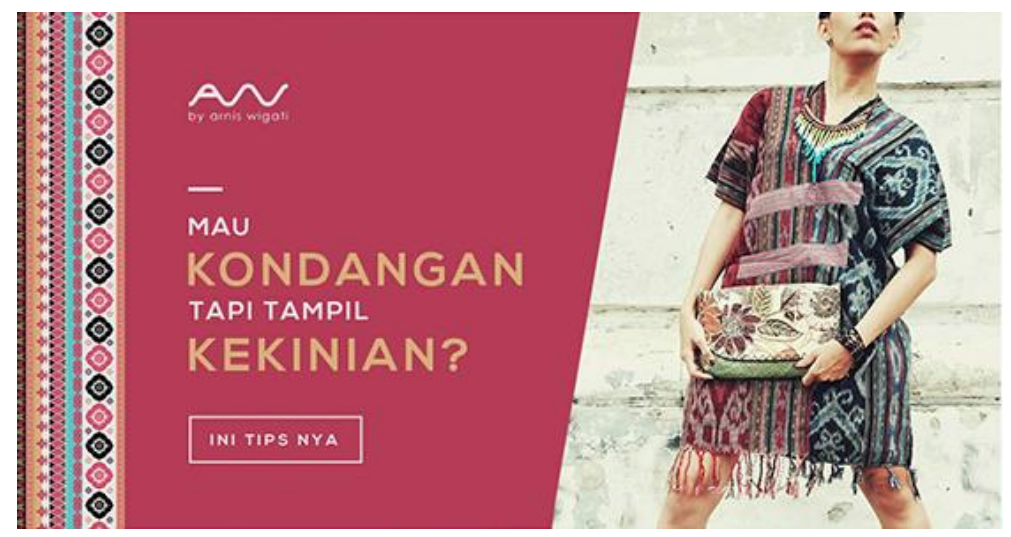

Gambar 5.2 Facebook dan Twitter Ads 
3. Instagram Ads

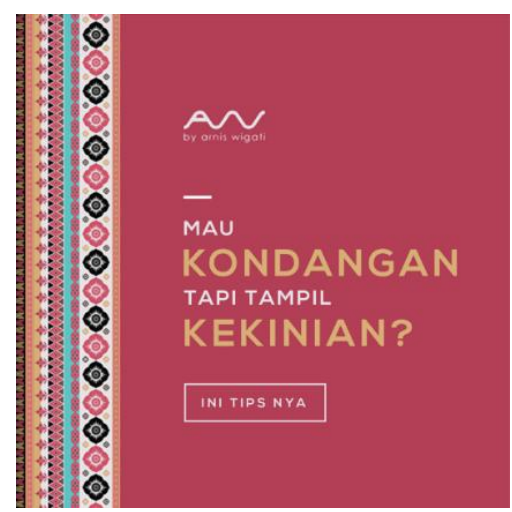

Gambar 5.3 Instagram Ads

4. Google Ads
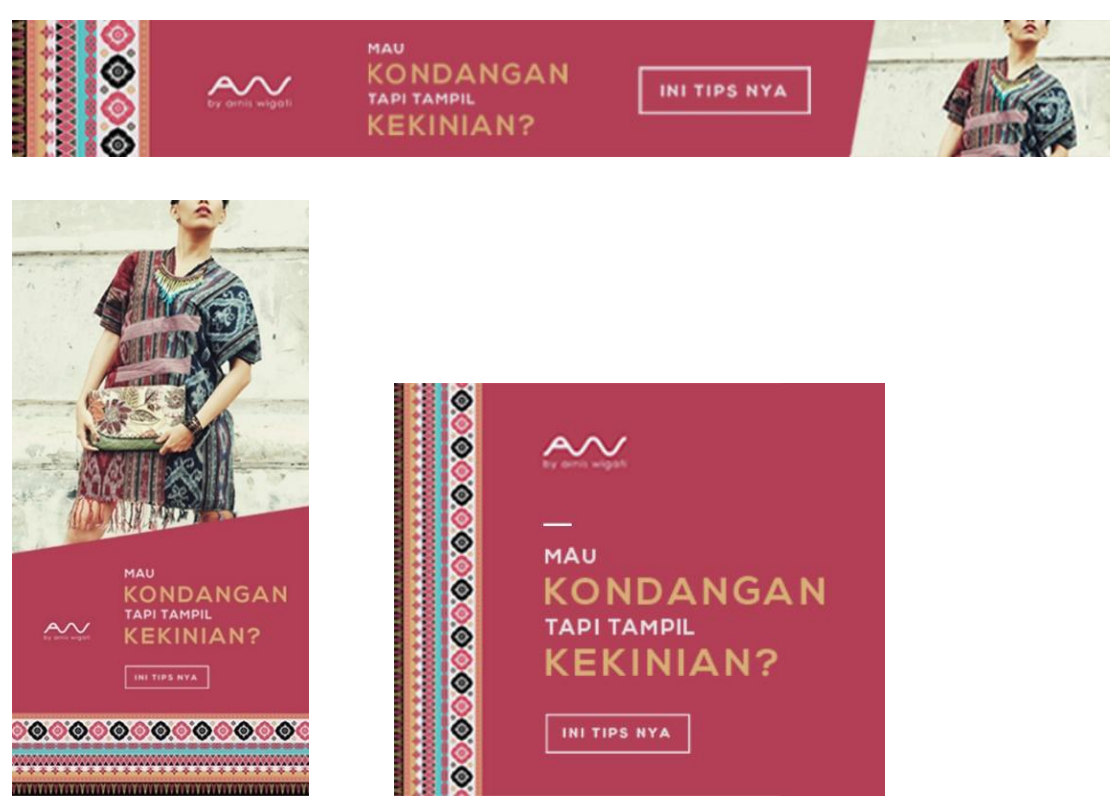

Gambar 5.4 Google Ads

\section{KESIMPULAN}

Berdasarkan hasil penelitian dan perancangan yang telah penulis lakukan, maka dapat disimpulkan bagaimana merancang media promosi efektif untuk meningkatkan brand awareness perusahaan Arnis Wigati sebagai berikut: 
1. AW memanfaatkan perancangan media promosi dengan menggunakan strategi inbound marketing, yaitu melalui media digital karena memiliki jangkauan yang luas dan mudah diterima oleh target audiens.

2. AW menggunakan blog yang diisi konten-konten berkualitas disesuaikan dengan hobi atau kebiasaan target audiens. Pada blog, calon konsumen akan diminta untuk memasukan email agar berlangganan newsletter dari AW bertujuan agar calon konsumen semakin aware dengan produk perusahaan.

3. AW menggunakan social media ads yang akan muncul pada media sosial calon konsumen AW dengan konten yang diambil dari blog untuk langsung mengarahkan calon konsumen menuju blog ketika mengklik iklan.

4. Konsep perancangan menyesuaikan dengan perilaku konsumen AW dengan mengkombinasikan antara unsur kontemporer dan tradisional agar menarik perhatian calon konsumen dan semakin aware dengan AW.

\section{DAFTAR PUSTAKA}

Hendraswati. 2012. Sasirangan Kain Traditional Banjar. Pustaka Book Publisher, Yogyakarta.

Kartajaya, Hermawan. 2010. Brand Operation. Erlangga, Jakarta.

Kotler, Philip. 2003. Marketing Management (Edisi 11). Prentice Hall. New Jersey. Kotler, Philip \& Amstrong, Gary. 2008. Prinsip-Prinsip Pemasaran (Edisi. 12. Jilid. 1) Erlangga. Jakarta.

Kotler, Philip \& Keller, Kevin Lane. 2016. Marketing Management (15th Edition). Pearson Education Limited. Harlow. 
Morissan. 2010. Periklanan: Komunikasi Pemasaran Terpadu, Prenada Media Group, Jakarta.

Mulyani. 2014. Panduan Optimalisasi Media Sosial Untuk Kementrian Perdagangan RI, Pusat Hubungan Masarakat, Jakarta.

Schiffman, Leon G \& Kanuk, Leslie L. 2000. Manajemen Pemasaran dan Pemasaran Jasa (Edisi 4). CV. Linda Karya. Bandung.

Sistaningrum, Edyningtyas. 2002. Manajemen Penjualan Produk. Kanisius. Yogyakarta.

Soewardikoen, Didit Widiatmoko. 2013. Metedologi Penelitian dari Seminar ke Tugas Akhir. Dinamika Komunika, Bandung.

Supriyono, Rakhmat. 2010. Desain Komukasi Visual Teori dan Aplikasi. C.V Andi Offset. Yogyakarta.

Swasty, Wirania. 2010. A-Z Warna Interior Rumah Tinggal, Griya Kreasi, Jakarta.

Tinarbuko, Sumbo. 2009. Semiotika Komunikasi Visual. Jalasutra. Yogyakarta.

\section{Website}

http://www.hubspot.com/inbound-marketing/, 31-10-2016, 03:52 WIB

http://www.instagram.com/vatthuofficial, 10-11-2016, 05:00 WIB

http://www.instagram.com/torajamelo, 10-11-2016, 05:10 WIB

http://www.vatthu.com/, 10-11-2016, 05:20 WIB

http://www.torajamelo.com/, 10-11-2016, 05:30 WIB

http://www.inkcreativa.com/aisas-marketing/, 10-11-2016, 06:30 WIB 